\title{
Introduction to the May 2021 Issue
}

\section{Charles B. Hodges ${ }^{1}$}

Published online: 16 April 2021

(C) Association for Educational Communications \& Technology 2021

This issue of TechTrends, is a special issue guest edited by a team from the the University of North Carolina at Charlotte: Drew Polly, Erik J. Byker, and Madelyn W. Colonnese. They have put together a great issue for you on the topic of "Future Directions for K-12 Technology-Enhanced Learning Environments". Their Guest Editors' Notes provide a detailed context for the issue. I appreciate the months of hard work and collaboration they did to put this issue together. I also appreciate the authors who submitted their work to the issue and the reviewers who spent time providing feedback on the papers! While the papers are tied together by the theme of the issue, I think you will find them to have a good degree of variation too. The issue also includes some of our regular columns. Be sure to read the Reimagining Technology, Creativity \& Learning, the History Corner, Graduate Member Musings, and the Book Reviews column, which appears after all of the original papers. I hope you find the issue interesting!

A few updates about TechTrends:

In this issue the role of column editor for the Graduate Member Musings column transitions from one individual to another. Jennifer Englund, who is an employee and doctoral student at the University of Minnesota-Twin Cities, has led the column as editor for some time. She has done a great job and I appreciate her hard work and professionalism. She is stepping away from the column to focus on finishing her dissertation. I wish her much success in all future endeavors! Assuming the role of editor for Graduate Member Musings is Kae Novak, a doctoral student at the University of Colorado-Denver. I am looking forward to working with Kae!

As Editor-in-Chief I received word from Springer Nature that in a recent survey of TechTrends authors $91 \%$ of respondents were satisfied with their overall experience with the journal. Additionally, $100 \%$ of the participants agreed that the review process improved their papers and that the editors managed the peer review process well. This type of feedback is great to see. These positive experiences by the authors would not be possible without the work of a large team of guest editors, reviewers, the editorial board, AECT, and the staff at Springer Nature. It is a pleasure to work with such a great team! Thank you all!

As always, if you are interested in submitting a manuscript to TechTrends, or if you want to be a reviewer, please contact me. Encourage your colleagues to submit their work to TechTrends, to read TechTrends, and to consider joining AECT! If you have a question about the journal, my phone number is $912-478-0497$ and my email address is chodges@georgiasouthern.edu. Email is the best way to reach me. Also, you can follow TechTrends on Twitter: @ AECTTechTrends.

Publisher's Note Springer Nature remains neutral with regard to jurisdictional claims in published maps and institutional affiliations.

Charles B. Hodges

chodges@georgiasouthern.edu

1 Georgia Southern University, Statesboro, GA, USA 